\title{
Mechanical properties of sputtered silicon nitride thin films
}

\author{
M. Vila ${ }^{a}$ \\ Instituto de Ciencia de Materiales de Madrid, Consejo Superior de Investigaciones Científicas, \\ Cantoblanco, 28049-Madrid, Spain \\ D. Cáceres \\ Departamento Física, Escuela Politécnica Superior, Universidad Carlos III de Madrid, Avda. Universidad, \\ 30 28911-Leganés, Spain \\ C. Prieto \\ Instituto de Ciencia de Materiales de Madrid, Consejo Superior de Investigaciones Científicas, \\ Cantoblanco, 28049-Madrid, Spain
}

(Received 9 May 2003; accepted 22 September 2003)

\begin{abstract}
Silicon nitride thin films were prepared by reactive sputtering from different sputtering targets and using a range of $\mathrm{Ar} / \mathrm{N}_{2}$ sputtering gas mixtures. The hardness and the Young's modulus of the samples were determined by nanoindentation measurements. Depending on the preparation parameters, the obtained values were in the ranges 8-23 and 100-210 GPa, respectively. Additionally, Fourier-transform infrared spectroscopy, Rutherford backscattering spectroscopy, and x-ray diffraction were used to characterize samples with respect to different types of bonding, atomic concentrations, and structure of the films to explain the variation of mechanical properties. The hardness and Young's modulus were determined as a function of film composition and structure and conditions giving the hardest film were found. Additionally, a model that assumes a series coupling of the elastic components, corresponding to the $\mathrm{Si}-\mathrm{O}$ and $\mathrm{Si}-\mathrm{N}$ bonds present in the sample has been proposed to explain the observed variations of hardness and Young's modulus. () 2003 American Institute of Physics. [DOI: 10.1063/1.1626799]
\end{abstract}

\section{INTRODUCTION}

The use of mechanically resistant coatings is a common practice in many industries. Coatings of less than $1 \mu \mathrm{m}$ in thickness are of increasing interest for use in compact electronic components, ${ }^{1,2}$ micromechanical systems, and for decorative purposes. ${ }^{3,4}$ In order to develop additional surface functions, such as excellent abrasion and corrosion resistance in materials, hard films deposited by physical vapor deposition and chemical vapor deposition $(\mathrm{CVD})^{5}$ techniques have been widely applied in recent years. ${ }^{6}$

The dielectric properties and conduction mechanism of silicon nitride thin films have been extensively studied ${ }^{7,8}$ due to their application in microelectronics as gate dielectrics in thin film transistors ${ }^{9}$ or in metal-oxide-semiconductor integrated circuits as thin nitride-oxide stacked layers. ${ }^{10}$ Silicon nitride films are commonly prepared by CVD techniques. These films contain relatively high amounts of hydrogen, which can lead to a degradation of films in subsequent high temperature processing steps. ${ }^{11}$ Therefore, sputtering is an interesting thin film preparation technique for all silicon nitride applications where low process temperatures are desired, low hydrogen contents in the films are required (because no hydrogen content is obtained), or where the stoichiometry of the films should be controlled ${ }^{12}$ for example to obtain higher hardness of the film. ${ }^{13}$

Hardness values have been estimated for $\alpha-\mathrm{Si}_{3} \mathrm{~N}_{4}$ and amorphous $\mathrm{Si}_{3} \mathrm{~N}_{4}\left(a-\mathrm{Si}_{3} \mathrm{~N}_{4}\right)$ by molecular dynamics calcu-

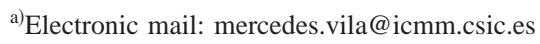

lations, giving values of 50.3 and $31.5 \mathrm{GPa}$, respectively. ${ }^{14}$ To evaluate the quality of these thin films, it has become increasingly necessary to measure their mechanical properties such as hardness and Young's modulus. A wide range of hardness values of silicon nitride thin films has been reported. Samples prepared by plasma-enhanced CVD are in the 14-19 GPa range, ${ }^{15,16}$ and low pressure CVD samples present hardness of $21 \mathrm{GPa},{ }^{17}$ while values of $23 \mathrm{GPa}$ has been reported for stoichiometric silicon nitride thin films prepared by CVD at high temperature. ${ }^{16}$

In this work, we present the mechanical properties of sputtered silicon nitride thin films prepared under different conditions, as well as a structural and compositional characterization study to explain the obtained behavior. In order to study the preparation conditions, two different types of targets were selected: a high-density homemade ceramic $\beta-\mathrm{Si}_{3} \mathrm{~N}_{4}$ target and a pure silicon commercial target.

\section{EXPERIMENT}

Silicon nitride thin films were grown on $\mathrm{Si}(100)$ and graphite substrates by using a planar 2 in. magnetron source (Angstrom Science) operated by a Huttinger rf-power supply. Typical rf power was $100 \mathrm{~W}$. Two different targets were used: (i) a homemade fully dense ceramic $\beta-\mathrm{Si}_{3} \mathrm{~N}_{4}$ prepared by hot pressing, ${ }^{18}$ and (ii) a pure silicon target (from Goodfellow) in order to perform reactive sputtering. Targets were circular in form with a thickness of $3 \mathrm{~mm}$, and were mechanically clamped to the water-cooled rf electrode. The vacuum system provides a residual pressure near 1 
$\times 10^{-7}$ mbar. Ar, $\mathrm{N}_{2}$ (both with purity of $99.999 \%$ ) and their binary mixed gases were used as sputtering gases, the gas flow rate being adjusted with two independent mass flow controllers to obtain a pressure of $5.0 \times 10^{-3}$ mbar for the sputtering deposition. All samples were grown, after a wellcontrolled presputtering time, at room temperature (unless otherwise indicated) to give a similar thickness of about 0.4 $\mu \mathrm{m}$. Annealing experiments were carried out at 1200 and $1350^{\circ} \mathrm{C}$ in vacuum with a base pressure of $1 \times 10^{-2}$ mbar.

Nanoindentation experiments were performed with a Nanoindenter II s (Nano Instruments, Inc., Knoxville, TN) mechanical properties microprobe. All tests were performed at room temperature with a diamond Berkovich (three-sided pyramid) indenter tip. Each specimen was tested using the continuous stiffness measurement technique developed by Pethica and Oliver. ${ }^{19,20}$

Silicon nitride thin films were also characterized by the Rutherford backscattering spectroscopy (RBS) techniques using the $3 \mathrm{MV}$ tandem accelerator of the Centro Nacional de Aceleradores at Sevilla.

\section{RESULTS AND DISCUSSION}

\section{A. Silicon nitride films prepared from a $\mathrm{Si}_{3} \mathrm{~N}_{4}$ ceramic target}

As described elsewhere, ${ }^{18}$ the ceramic $\mathrm{Si}_{3} \mathrm{~N}_{4}$ target was prepared with an addition of $10 \%$ wt $\mathrm{Y}_{2} \mathrm{O}_{3}$ by hot pressing at a maximum temperature of $1750{ }^{\circ} \mathrm{C}$ in a flowing $\mathrm{N}_{2}$ atmosphere of $0.1 \mathrm{MPa}$. The sintered material was fully dense and had a microstructure consisting of $\beta-\mathrm{Si}_{3} \mathrm{~N}_{4}$ grains and Y-silicate grain boundary phases. The target had a significant additive content in order to produce a hard enough sintered ceramic and it is important to study its validity in fabricating these thin films. The films were grown with different mixtures of sputtering gases but in this work we will only refer to $50 \% \mathrm{~N}_{2} / 50 \% \mathrm{Ar}$ and $100 \% \mathrm{~N}_{2}$ growth samples. Samples made with a nitrogen gas concentration smaller than $50 \%$ contained a considerable amount of oxygen.

Conventional hardness is equivalent to the actual pressure under the indenter, i.e., the applied load divided by the actual projected area of contact. Figure 1 shows the hardness and Young's modulus of the films as a function of the contact depth of the indenter tip. Both graphs, for hardness and Young's modulus, present values almost constant in the range represented indicating that these values are unaffected by the presence of the silicon substrate. $H$ and $E$ values obtained for the films, taken as the curve maximum of the indentation contact displacement graphics, appear in Table I. Hardness and Young's modulus increased slightly for samples prepared with higher nitrogen concentration in the sputtering atmosphere.

The hardness values for the films were close to $18 \mathrm{GPa}$. Although there is appreciable oxygen content in the films, this value is higher than the $9 \mathrm{GPa}$ obtained for a silicon dioxide sample (also included in Fig. 1 for comparison), but is clearly in the low range of values reported for silicon nitride films.

In order to understand the observed behavior we have performed RBS experiments to determine the atomic

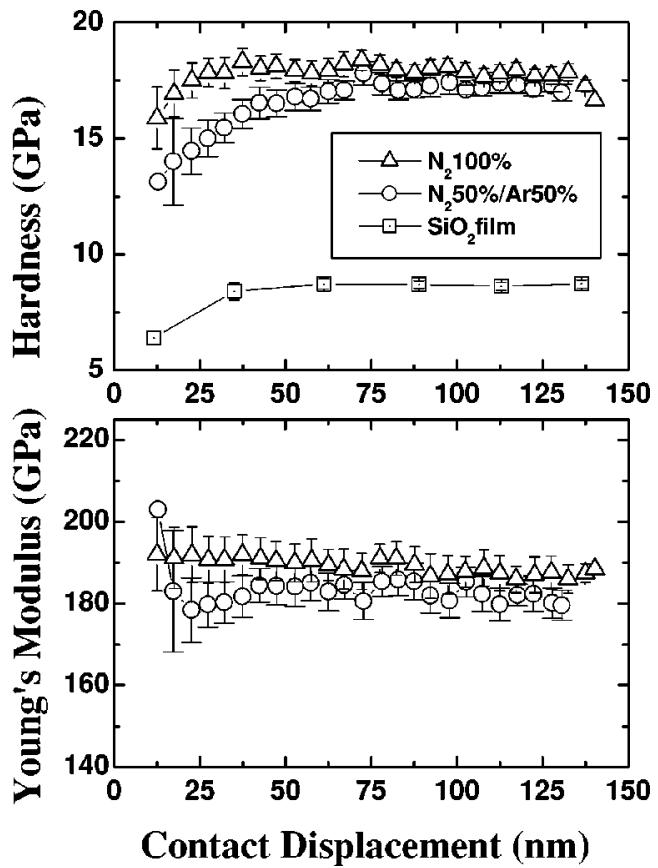

FIG. 1. Hardness and Young's modulus vs indentation contact displacement for silicon nitride films prepared from the ceramic $\mathrm{Si}_{3} \mathrm{~N}_{4}$ target.

composition, ${ }^{12}$ the results are also given in Table I in terms of the obtained $\mathrm{N} / \mathrm{Si}, \mathrm{O} / \mathrm{Si}$, and $\mathrm{O} / \mathrm{Si}$ ratios.

When the sputtering gas is changed there is a modification of the film composition, ${ }^{21}$ which influences several physical properties, as has been reported earlier for refractive index and resistivity. ${ }^{22}$ The present results indicate that the working atmosphere during the preparation also influences the mechanical properties of the films.

Taking into account the obtained nitrogen/silicon and oxygen/silicon ratios it seems that the presence of oxygen is correlated with the decrease of the hardness and elastic modulus values. The highest hardness value obtained was 18.2 GPa for the sample grown in a $\mathrm{N}_{2}$ atmosphere, which is of the same order as that reported for samples prepared by CVD techniques. This sample is $\mathrm{N}$ rich (overstoichiometric) and with the smallest oxygen content obtained from this target. It can be noted that that the high oxygen contents in the films probably originated from the target additives that are needed to give a high-density ceramic target and are probably not possible to reduce by further modification of the sputtering conditions.

\section{B. Silicon nitride films prepared from a Si target}

To avoid oxygen coming from the target, silicon nitride thin films can be prepared by reactive sputtering with a pure silicon target. For that purpose, a series of samples were prepared under different sputtering conditions. RBS analysis of the new samples series has been carried out, ${ }^{12}$ and the obtained $\mathrm{N} / \mathrm{Si}, \mathrm{O} / \mathrm{N}$, and $\mathrm{O} / \mathrm{Si}$ ratios are given in Table I.

As expected, samples prepared in this way exhibit lower oxygen concentration for a given gas atmosphere than samples grown from the silicon nitride target; there was still a small amount inside the sample, probably coming from the residual vacuum. Figure 2 shows the correlation of both the 
TABLE I. Summary of hardness $(H)$ and Young's modulus $(E)$ for all studied samples. The three last columns give the element ratio obtained by RBS.

\begin{tabular}{cccccccc}
\hline \hline Target & $\begin{array}{c}\text { Gas } \\
\text { concentration }\end{array}$ & $\begin{array}{c}\text { Thermal } \\
\text { treatment }\end{array}$ & $\begin{array}{c}H \\
(\mathrm{GPa})\end{array}$ & $\begin{array}{c}E \\
(\mathrm{GPa})\end{array}$ & $\begin{array}{c}\mathrm{N} / \mathrm{Si} \\
\text { ratio }\end{array}$ & $\begin{array}{c}\mathrm{O} / \mathrm{N} \\
\text { ratio }\end{array}$ & $\begin{array}{c}\mathrm{O} / \mathrm{Si} \\
\text { ratio }\end{array}$ \\
\hline $\mathrm{SiO}_{2}$ & $\mathrm{Ar} 50 \%-\mathrm{O}_{2} 50 \%$ & RT-grown & 9 & & $\cdots$ & $\cdots$ & 2.0 \\
$\beta-\mathrm{Si}_{3} \mathrm{~N}_{4}$ & $\mathrm{Ar} 50 \%-\mathrm{N}_{2} 50 \%$ & RT-grown & $17.0 \pm 0.4$ & $185 \pm 5$ & 1.7 & 0.21 & 0.43 \\
$\beta-\mathrm{Si}_{3} \mathrm{~N}_{4}$ & $\mathrm{~N}_{2} 100 \%$ & RT-grown & $18.2 \pm 0.6$ & $192 \pm 5$ & 2.0 & 0.19 & 0.37 \\
$\mathrm{Si}$ & $\mathrm{Ar} 70 \%-\mathrm{N}_{2} 30 \%$ & RT-grown & $9 \pm 1$ & $118 \pm 9$ & 0.48 & 1.36 & 0.66 \\
$\mathrm{Si}$ & $\mathrm{Ar} 50 \%-\mathrm{N}_{2} 50 \%$ & RT-grown & $12 \pm 1$ & $144 \pm 8$ & 1.33 & 0.25 & 0.33 \\
$\mathrm{Si}$ & $\mathrm{Ar} 30 \%-\mathrm{N}_{2} 70 \%$ & RT-grown & $14 \pm 2$ & $162 \pm 13$ & 1.3 & 0.19 & 0.25 \\
$\mathrm{Si}$ & $\mathrm{Ar} 15 \%-\mathrm{N}_{2} 85 \%$ & RT-grown & $16 \pm 2$ & $179 \pm 9$ & 1.33 & 0.075 & 0.10 \\
$\mathrm{Si}$ & $\mathrm{N}_{2} 100 \%$ & RT-grown & $19 \pm 1$ & $201 \pm 7$ & 1.37 & 0.05 & 0.075 \\
$\mathrm{Si}$ & $\mathrm{N}_{2} 100 \%$ & $1200^{\circ} \mathrm{C}$-annealed & $16.4 \pm 0.4$ & $174 \pm 5$ & & & \\
$\mathrm{Si}$ & $\mathrm{N}_{2} 100 \%$ & $1350^{\circ} \mathrm{C}$-annealed & $18.0 \pm 0.5$ & $183 \pm 5$ & & & \\
$\mathrm{Si}$ & $\mathrm{N}_{2} 100 \%$ & $850^{\circ} \mathrm{C}$-grown & $23.4 \pm 1.0$ & $210 \pm 7$ & 1.22 & 0 & 0 \\
\hline \hline
\end{tabular}

oxygen content in the sample and the deposition rate with the nitrogen content of the gas atmosphere. It can be seen that the oxygen content decreased with the deposition rate, associated with higher nitrogen concentration in the sputtering atmosphere. The explanation of this behavior could be related to the fact that there is not enough time for the nitridation process at higher deposition rates; silicon dangling bonds join more easily to the oxygen that remains as base pressure contamination and this reaction is more effective for high growth rates.

The measured mechanical properties of this silicon nitride series are shown in Fig. 3. As in the case of the optical and electrical properties, ${ }^{23}$ there is a clear influence of the sputtering conditions on the film mechanical properties. Hardness $(H)$ and elastic modulus $(E)$ are given in Table I. At small oxygen contents, both properties are correlated inversely with the oxygen concentration. The results are in
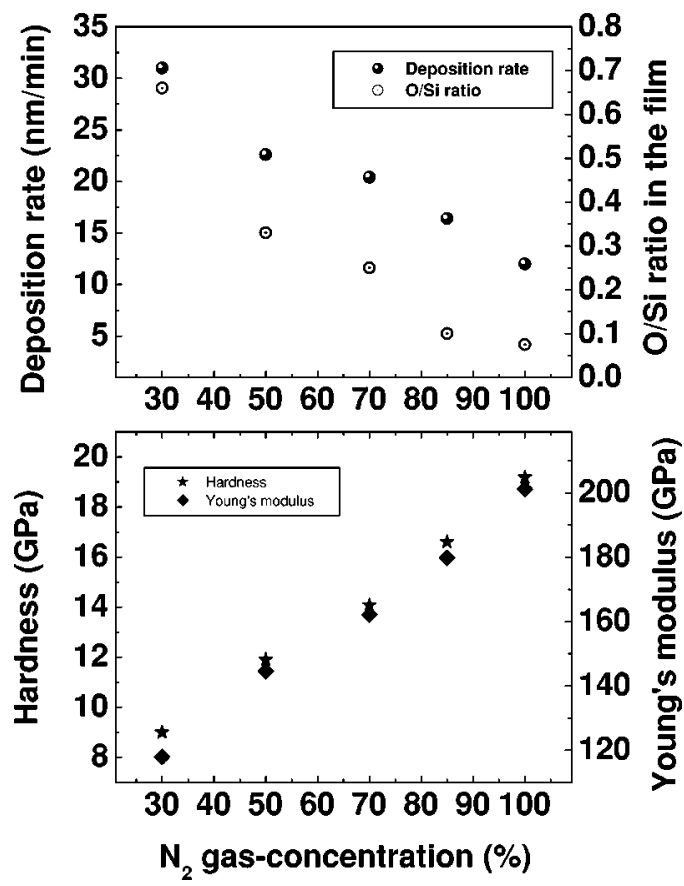

FIG. 2. Variation of the deposition rate and $\mathrm{O} / \mathrm{Si}$ ratio as well as the film properties as a function of the nitrogen concentration in the sputtering working gas for films prepared from the silicon target. good agreement with the fact that a mixture of siliconoxygen and silicon-nitrogen bonds forms samples. Depending on its ratio, the film hardness and Young's modulus decrease when the oxygen concentration increases. It is clear that silicon oxide has smaller values for the hardness and elastic modulus than silicon nitride and the existence of $\mathrm{Si}-\mathrm{O}$ bonds embedded in the silicon nitride thin films tends to lower the hardness and elastic modulus down to values similar to the silicon oxide.

Samples obtained from reactive sputtering can be described as amorphous $\mathrm{Si}_{3} \mathrm{~N}_{4}$ having an oxygen concentration that depends on the deposition parameters. The elastic properties strongly depend on the oxygen concentration in such a way that the elastic modulus and the hardness have values between those corresponding to amorphous silicon oxide and to amorphous silicon nitride. For such behavior where the elastic constant of a mixture takes values between those corresponding to the pure components a series coupling of elastic entities should be considered. A similar model has been used to explain the elastic constant of sol-gels materials ${ }^{24}$

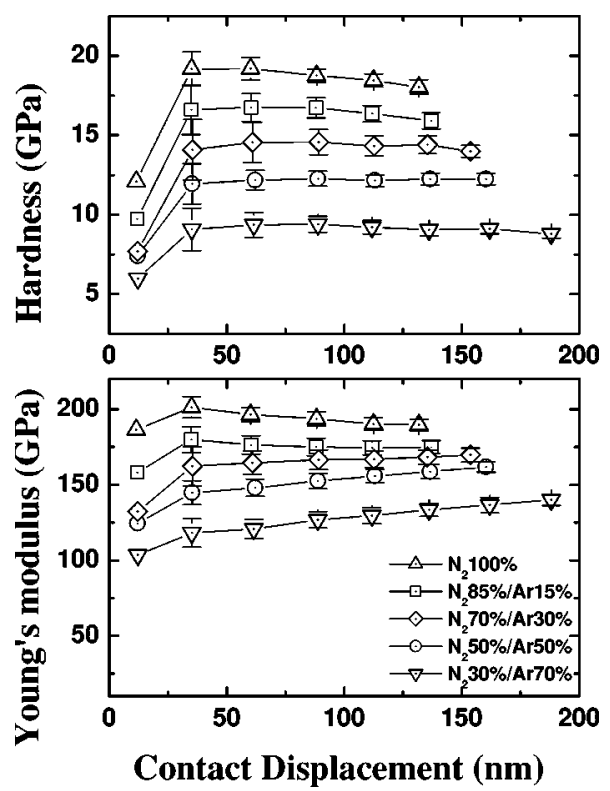

FIG. 3. Hardness and Young's modulus vs indentation contact displacement for silicon nitride films prepared from the pure Si target. 


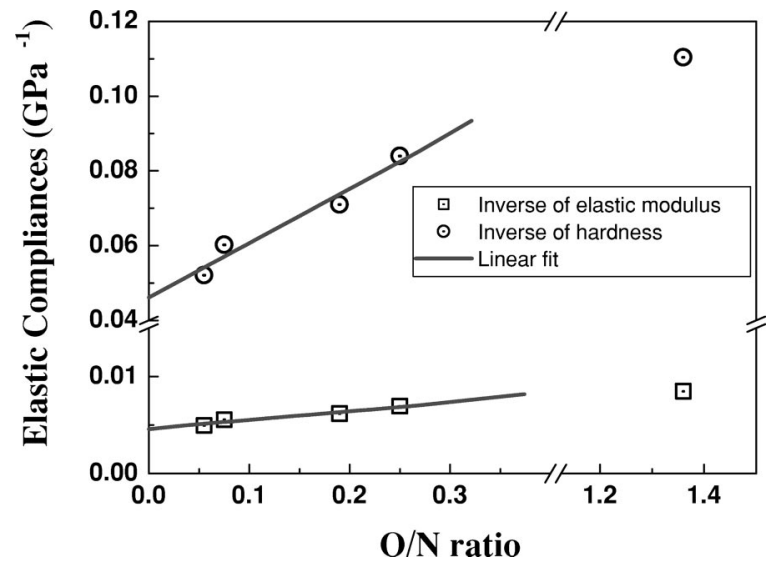

FIG. 4. Inverse of the hardness and Young's modulus (compliances) as a function of the oxygen content.

and superlattices. ${ }^{25}$ This model provides an effective elastic constant that can be calculated by the following expression:

$$
\frac{1}{C_{\text {eff }}}=\frac{f_{(\mathrm{Si}-\mathrm{O})}}{C_{(\mathrm{Si}-\mathrm{O})}}+\frac{f_{(\mathrm{Si}-\mathrm{N})}}{C_{(\mathrm{Si}-\mathrm{N})}},
$$

where $C_{(\mathrm{Si}-\mathrm{O})}$ and $C_{(\mathrm{Si}-\mathrm{N})}$ are the elastic constants corresponding to the silicon-oxygen and silicon-nitrogen chemical bonds that should be close to the elastic constants of pure silicon oxide and pure silicon nitride compounds; and $f_{(\mathrm{Si}-\mathrm{O})}$ and $f_{(\mathrm{Si}-\mathrm{N})}$ are the molar fraction of both kinds of bonds. In the low oxygen concentration range Eq. (1) can be approximated by

$$
\frac{1}{C_{\mathrm{eff}}}=\frac{f_{(\mathrm{Si}-\mathrm{O})}}{f_{(\mathrm{Si}-\mathrm{N})}} \frac{1}{C_{(\mathrm{Si}-\mathrm{O})}}+\frac{1}{C_{(\mathrm{Si}-\mathrm{N})}},
$$

where the $f_{(\mathrm{Si}-\mathrm{O})} / f_{(\mathrm{Si}-\mathrm{N})}$ ratio between the two molar fractions is proportional to the oxygen/nitrogen ratio measured by RBS. It can be noted that this estimate can be used for both hardness and elastic modulus, because both are related to the elastic constant $C_{i j}$ tensor that depends microscopically on the types of atomic bonds.

For our samples, Fig. 4 shows the inverse of the hardness and Young's modulus (referred to as elastic compliances) as a function of $\mathrm{O} / \mathrm{N}$ ratio. At low oxygen content it is clear that both properties follow a linear dependence as predicted by Eq. (2). One can obtain the expected hardness and Young's modulus values for the oxygen-free amorphous silicon nitride film by linear extrapolation to the ordinate at the origin, which yields values of 23.9 and $215 \mathrm{GPa}$ for the hardness and elastic modulus, respectively.

\section{Thermal treatments}

Another way of improving the hardness of the film is to approach bulk properties by transforming amorphous silicon nitride into crystalline silicon nitride. Previous studies have shown that amorphous CVD-prepared silicon nitride films can crystallize $e^{26}$ if annealed at $1350^{\circ} \mathrm{C}$ for $1 \mathrm{~h}$. Here the hardest sample (that grown using the pure silicon target and $100 \%$ nitrogen sputtering atmosphere at $5 \times 10^{-3}$ mbar) has been annealed in rough vacuum for one hour at 1200 and
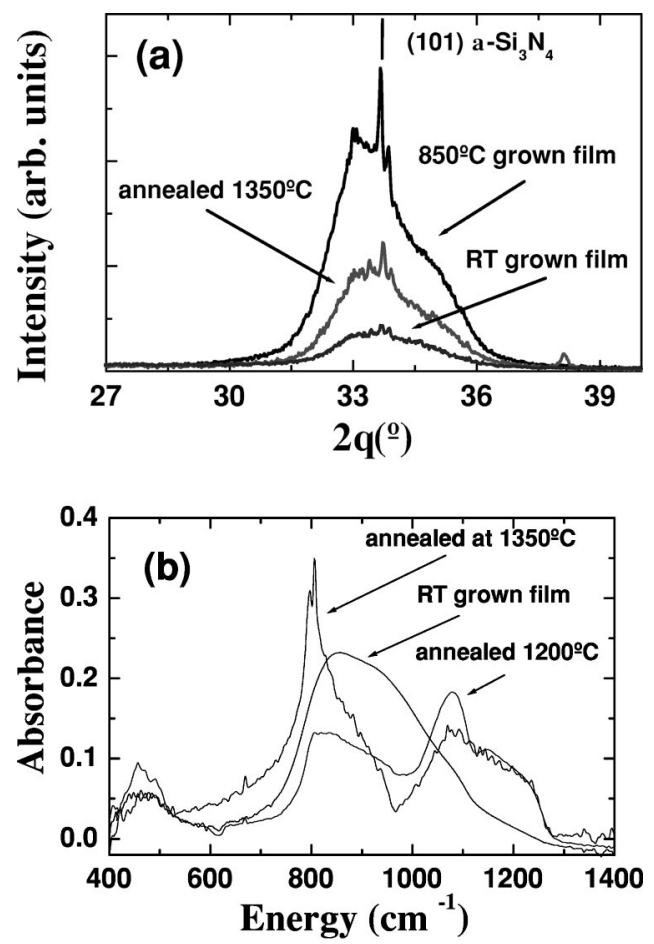

FIG. 5. (a) X-ray diffraction spectra and (b) infrared spectra for samples following different thermal treatments. The position of (101) diffraction peak of the $\alpha-\mathrm{Si}_{3} \mathrm{~N}_{4}$ phase is indicated.

$1350^{\circ} \mathrm{C}$. Additionally, a sample was prepared under the same conditions but at a substrate temperature of $850^{\circ} \mathrm{C}$ to compare both methods of crystallization.

X-ray diffraction spectra represented in Fig. 5(a) show a change in the film structure. The room temperature prepared sample exhibited a broad peak corresponding to an amorphous phase. Annealing at $1350{ }^{\circ} \mathrm{C}$ gave rise to an increase in intensity of this broad peak and the appearance of narrow peaks at positions corresponding to the $\alpha-\mathrm{Si}_{3} \mathrm{~N}_{4}$ phase. A similar but more pronounced effect was obtained when the sample was prepared at a substrate temperature of $850^{\circ} \mathrm{C}$. In these samples, it is concluded that only a small portion of the film has been crystallized. The amorphous form remains as the majority phase even in the sample deposited at $850^{\circ} \mathrm{C}$.

Additionally, some changes in the bonding structure were to be expected. Figure 5(b) shows the IR transmission spectra of silicon nitride films after thermal treatment compared to the as-grown sample at room temperature. A change of the IR spectra due to the annealing process is apparent. The IR absorption spectrum of partially crystallized silicon nitride reveals the typical narrow bands of the crystalline phase around $800 \mathrm{~cm}^{-1}$, as well as, the formation of the $1060 \mathrm{~cm}^{-1}$ band typical of silicon oxide. The $1200^{\circ} \mathrm{C}$ annealed sample shows mainly an increase of the characteristic contribution of the $\mathrm{Si}-\mathrm{O}$ bonds while the sample annealed at $1350{ }^{\circ} \mathrm{C}$ shows in addition a very narrow band near $800 \mathrm{~cm}^{-1}$ characteristic of the silicon nitride crystallization process. Unfortunately, annealing was performed in rough vacuum; at high temperatures, the base pressure provides a source of oxygen that reacts with the film and gives rise to silicon oxynitride films. It is to be concluded that a degrada- 

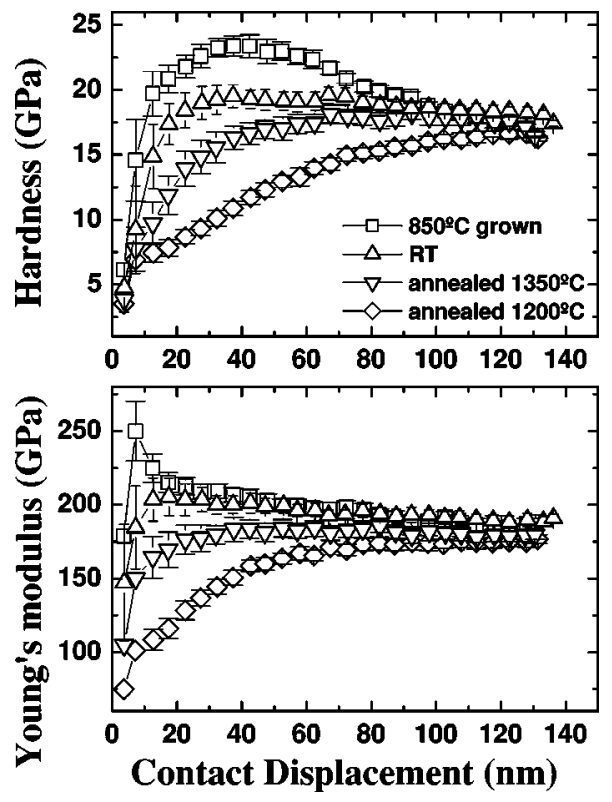

FIG. 6. Hardness and Young's modulus vs indentation contact displacement for silicon nitride films following different thermal treatments.

tion of the sample (in the sense of silicon oxide formation) occurs during the annealing under these conditions.

The results of nanoindentation measurements for these partially crystallized samples are shown in Fig. 6. It can be observed that the hardness and elastic modulus decreased for annealed samples. This effect is due to the poor vacuum annealing atmosphere that leads to an oxidation of the samples. Therefore, this higher oxide content, according to the model presented earlier, reduces the properties towards the lower values of silicon oxide. Nevertheless, the sample prepared at $850^{\circ} \mathrm{C}$ exhibited an increase in the hardness and elastic modulus up to 23.4 and $220 \mathrm{GPa}$, respectively, close to the model predicted values for the oxygen free samples. This result is in agreement with a change in the mechanical properties since the structure is near polycrystalline silicon nitride.

Finally, Fig. 7 presents the RBS data and the fit calculated with the RUMP version $2.0 \operatorname{code}^{27}$ for the sample prepared at $850{ }^{\circ} \mathrm{C}$. The results show that there is no oxygen inside the sample (only a small contribution of oxygen can be observed at the surface of the film, which is due to surface

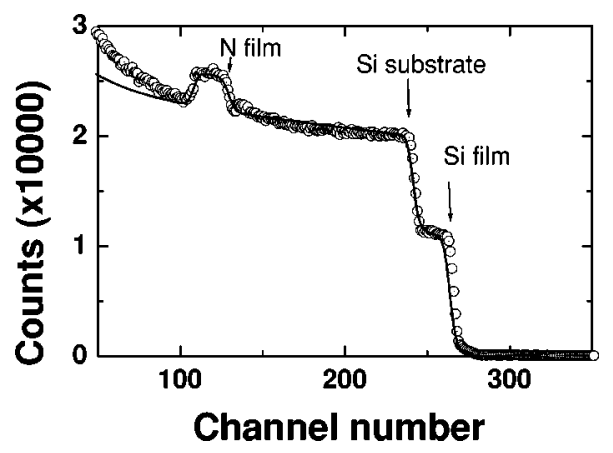

FIG. 7. RBS data of the silicon nitride film prepared at $850^{\circ} \mathrm{C}$. Open circles are experimental points and the continuous line is the calculated spectrum. oxidation) and corroborates the conclusion that the increase in the hardness and Young's modulus were due to the oxygen-free character.

It is worth noting that although the crystalline phase exhibits elastic constants much higher than those of amorphous silicon nitride, a small crystalline content embedded in a majority of amorphous phase is not expected to have a significant effect on elastic properties. This follows from the serial coupling model. Following Eq. (1), the model predicts a strong decrease in the properties when a stiff or hard phase is doped with a more compliant or softer phase, whereas, when a soft amorphous material is doped with a crystalline hard phase, the effect is not appreciable up to very high concentration of the hard phase.

\section{CONCLUSIONS}

Silicon nitride thin films have been prepared in a sputtering system with mixtures of Ar and $\mathrm{N}_{2}$ as sputtering gases and different targets, in order to study a combination of sputtering parameters to obtain an increase in the hardness and Young's modulus.

At room temperature and by reactive sputtering from a Si target, films have been grown with stoichiometry very close to $\mathrm{Si}_{3} \mathrm{~N}_{4}$ with a small amount of oxygen coming from the residual vacuum. The measured hardness and modulus show a clear inverse correlation with the oxygen content in the film composition, i.e., they increase with decreasing oxygen content. The hardness and Young's modulus values are in the ranges 9-19 and 118-200 GPa, respectively.

Another way of improving these results was to deposit the sample at high temperature $\left(850^{\circ} \mathrm{C}\right)$ when the sample became oxygen free and partially crystallized. The hardness and Young's modulus increased to 23.4 and $210 \mathrm{GPa}$, respectively.

Additionally, the deposited film hardness and elastic modulus could be predicted on the basis of a model that assumes a serial coupling of the elastic components corresponding to the $\mathrm{Si}-\mathrm{O}$ and $\mathrm{Si}-\mathrm{N}$ bonds present in the sample. This model provides two limits for hardness and Young's modulus corresponding to pure silicon oxide and silicon nitride amorphous materials. The validity of this model was demonstrated by the observed linear behavior of the elastic compliances and inverse hardness versus the oxygen content in the samples. This also permitted a prediction of the hardness and Young's modulus values of an oxygen free silicon nitride amorphous film by linear extrapolation. Moreover, oxygen free, partially crystallized samples also exhibited hardness and modulus values fully in agreement with the serial coupling model.

${ }^{1}$ M. J. Powell, B. C. Easton, and O. F. Hill, Appl. Phys. Lett. 38, 794 (1981).

${ }^{2}$ H. E. Moes and E. Vanderkerckhave, in Silicon Nitride and Silicon Dioxide Thin Insulating Films, edited by V. J. Kapoor and K. T. Hankins (The Electrochemical Society, Pennington, NJ, 1987).

${ }^{3}$ A. K. Sinha, Solid State Technol. 133, April (1980).

${ }^{4}$ A. R. Reinberg, J. Electron. Mater. 8, 345 (1979).

${ }^{5}$ J. L. Vössen and W. Kern, Thin Film Processes (Academic, London, 1978).

${ }^{6}$ J. Musil, J. Vyskocil, and S. Kadlek, in Physics of Thin Films, edited by M. H. Francombe and J. L. Vossen (Academic, San Diego, 1993), Vol. 17. 
${ }^{7}$ H. Y. Yang, N. Niimi, and G. Lucovsky, J. Appl. Phys. 83, 2327 (1998).

${ }^{8}$ B. De Salvo et al., J. Appl. Phys. 86, 2751 (1999).

${ }^{9}$ N. Lustig and J. Kanicki, J. Appl. Phys. 65, 3951 (1989).

${ }^{10}$ F. Chen, B. Li, R. A. Dufresne, and R. Jammy, J. Appl. Phys. 90, 1898 (2001).

${ }^{11}$ C. Savall, J. C. Bruyère, and J. P. Stoquert, Thin Solid Films 260, 174 (1995).

${ }^{12}$ M. Vila, C. Prieto, J. Garcia-Lopez, and M. A. Respaldiza, Nucl. Instrum. Methods Phys. Res. B 211, 199 (2003).

${ }^{13}$ H. P. Löbl and M. Huppertz, Thin Solid Films 317, 153 (1998).

${ }^{14}$ P. Walsh, A. Omeltchenko, R. K. Kalia, A. Nakano, P. Vashishta, and S. Saini, Appl. Phys. Lett. 82, 118 (2003).

${ }^{15}$ U. Beck, D. T. Smith, G. Reiners, and S. J. Dapkunas, Thin Solid Films 332, 164 (1998).

${ }^{16}$ J. Ashley Taylor, J. Vac. Sci. Technol. A 9, 2464 (1991).

${ }^{17}$ J. J. Balzac and W. D. Nix, J. Mater. Res. 7, 3242 (1996).

${ }^{18}$ M. I. Osendi, A. de Pablos, and P. Miranzo, Mater. Sci. Eng., A 308, 53 (2001).
${ }^{19}$ W. C. Oliver and G. M. Pharr, J. Mater. Res. 7, 1564 (1992).

${ }^{20}$ J. B. Pethica and W. C. Oliver, Mater. Res. Soc. Symp. Proc. 130, 13 (1989).

${ }^{21}$ M. Vila, J. A. Martín-Gago, A. Muñoz-Martín, C. Prieto, P. Miranzo, M. I. Osendi, J. García López, and M. A. Respaldiza, Vacuum 67, 513 (2002).

${ }^{22}$ M. Vila, C. Prieto, P. Miranzo, M. I. Osendi, and R. Ramírez, Surf. Coat. Technol. 151-152, 67 (2002).

${ }^{23}$ M. Vila, C. Prieto, and R. Ramírez, Thin Solid Films (to be published).

${ }^{24}$ M. García-Hernández, R. Jiménez, C. Prieto, J. J. Fuentes-Gallego, E. Blanco, and M. Ramírez-del-Solar, Appl. Phys. Lett. 69, 3827 (1996).

${ }^{25}$ A. de Bernabé, C. Prieto, D. Cáceres, I. Vergara, A. G. Every, and H. E. Fischer, Phys. Status Solidi A 188, 1023 (2001).

${ }^{26}$ V. I. Belyi et al., in Silicon Nitride in Electronics, Materials Science Monographs Vol. 34 (Elsevier, Amsterdam, 1988).

${ }^{27}$ Software designed for the analysis and simulation of RBS data by L. R. Doolittle and M. O. Thompson. Details can be found at http:// www.genplot.com 